\title{
Hearing Status in Young People Using Portable Audio Players
}

\author{
Małgorzata PAWLACZYK-ŁUSZCZYŃSKA ${ }^{(1)}$, Kamil ZABOROWSKI ${ }^{(1)}$ \\ Małgorzata ZAMOJSKA-DANISZEWSKA ${ }^{(1)}$, Paulina RUTKOWSKA-KACZMAREK ${ }^{(1)}$ \\ Adam DUDAREWICZ ${ }^{(1)}$, Mariola ŚLIWINSKA-KOWALSKA ${ }^{(2)}$ \\ (1) Department of Physical Hazards, Nofer Institute of Occupational Medicine \\ Św. Teresy 8, 91-348 Łódź, Poland; e-mail: Malgorzata.Pawlaczyk@imp.lodz.pl \\ (2) Audiology and Phoniatrics Clinic, Nofer Institute of Occupational Medicine \\ Św. Teresy 8, 91-348 Łódź, Poland
}

(received March 15, 2016; accepted November 24, 2016)

The aim of this study was to evaluate the hearing status in young adults using portable audio players (PAPs) in relation to their listening habits.

The study included 58 subjects, aged $22.8 \pm 2.8$ years, non-occupationally exposed to noise. Questionnaire inquiry aimed at collecting personal data, the information on PAPs usage habits, self-assessment of hearing status and identification of risk factors for noise-induced hearing loss (NIHL) were performed in study subjects. Hearing tests included pure-tone audiometry (PTA) and transient-evoked otoacoustic emission (TEOAE).

All subjects were PAPs users. Depending on listening habits they were divided into the subgroups of "frequent" users $(>1 \mathrm{~h} /$ day) and "non-frequent" users ( $\leq 1 \mathrm{~h} /$ day). There were no significant differences between subgroups in prevalence of NIHL risk factors and self-assessment of hearing status. However, frequent users more often complained of tinnitus and hyperacusis.

Majority $(81.9 \%)$ of participants had normal hearing. Nevertheless, $6.9 \%$ of audiograms showed highfrequency notches typical for NIHL. Both, the PTA and TEOAE indicated worse hearing in non-frequent users compared to frequent users. No significant differences in prevalence of high-frequency notches between subgroups were noted.

The outcomes do not support some previous studies results that the excessive exposure to music listened through PAPs might result in accelerating of development of NIHL loss in young adults.

Keywords: Portable Audio Players (PAPs); pure-tone audiometry; transient-evoked otoacoustic emissions (TEOAEs); hearing threshold levels; high-frequency notches; noise-induced hearing loss.

\section{Introduction}

Noise-induced hearing loss (NIHL) is still a worldwide leading environmental and occupational health risk in industrialized countries and the second most common form of sensorineural hearing impairment, after presbyacusis. However, contrary to occupational exposure, the risk of hearing loss due to environmental exposures to noise or sounds in general population is still not fully recognized.

Among leisure activities accompanied by loud sounds, frequent listening to music through portable audio players (PAPs) seems to be one of the most common sources of high-risk leisure noise, especially for young people.
According to current data approximately $88-90 \%$ of young people admit to listening to PAPs (VogeL et al., 2011; Pellegrino et al., 2013). It was also estimated that from $17 \%$ to $29 \%$ of teenagers and young adults (17\% in the USA, $18 \%$ in Chile, $22.4 \%$ in Canada, $27.4 \%$ in Italy, and $28.6 \%$ in the Netherlands) are at risk of developing NIHL (PORTNUFF et al., 2011; 2013; KeITH et al., 2011; MUCHNIK et al., 2012; Breinbauer et al., 2012; Figueiredo et al., 2011; SUlAiman et al., 2013).

Furthermore, the actual hearing loss $(\geq 25 \mathrm{~dB}$ HL at one or more standard audiometric frequencies) was observed in $7.3 \%$ among 177 young Malaysian PAPs users (Sulaiman et al., 2013). Over 3 times higher prevalence of tinnitus was also found in young Brazil- 
ian PAPs users compared to non-users (28\% vs. $8 \%$ ) (FigueIREDo et al., 2011). Thus, increasing number of teenagers using portable audio players at high or very high volume settings for several hours a day might result in an increased prevalence of noise-induced hearing loss in the older age of today's young generation.

Therefore, the overall objective of this study was to analyze the hearing status in young adults reporting usage of personal listening devices. In particular, it was attempted to evaluate the prevalence of early signs of NIHL in relation to listening habits.

\section{Methodology}

The study was carried out in young adults and it involved hearing tests and questionnaire surveys aimed at self-assessment of hearing ability and identification of risk factors for NIHL. Data on habits concerning the usage of PAPs were also collected. The study group comprised 58 volunteers, not exposed to occupational noise, aged from 18.0 to 28.6 years (mean \pm SD: $22.2 \pm 2.8$ years). They were recruited through advertisement and received financial compensation for their participation in the study. The study design and methods were approved by the Bioethical Commission of the Nofer Institute of Occupational Medicine, Lodz, Poland.

\subsection{Questionnaire surveys}

All study subjects filled in a questionnaire to collect information concerning: (i) age and gender, (ii) education and/or profession, (iii) self-assessment of hearing status, (iv) medical history (prior middle-ear diseases,ear surgery, etc.), (v) physical features (body weight, height, skin pigmentation), and (vi) lifestyle (smoking, noisy hobbies, using portable media players, attending disco/bars, rock concerts, etc.). Special attention was paid to PAP-listening behaviours, i.e. frequency (every day, several times a week, occasionally, etc.) and time of daily usage, preferred type of headphones and volume settings. Based on the time of daily usage of PAPs, the subjects were classified into the subgroup of frequent PAPs users (those listening to music through the device for at least 1 hour a day) or to the subgroup of non-frequent PAPs users (those listening to music through the device for less than 1 hour a day).

\subsection{Self-assessment of hearing capabilities}

All subjects provided information on hearingrelated symptoms such as hearing impairment, difficulties in hearing or understanding whisper, normal speech and speech in noisy environment, as well as presence of tinnitus and hyperacusis.
All subjects also completed a (modified) Amsterdam Inventory for Auditory Disability and Handicap ((m)AIADH) (MEIJER et al., 2003). This questionnaire consists of 30 questions, including 2 control questions not included in the assessment. The questions are divided into five parts (subscales) assessing separately: (i) the ability of discrimination (differentiation) of sounds (subscale I), (ii) auditory localization (subscale II), (iii) understanding speech in noise (subscale III), (iv) intelligibility in quiet (subscale IV), and (v) detection of sounds (subscale V).

The respondents reported how often they were able to hear effectively in the situations specified above. The four answer categories were as follows: almost never, occasionally, frequently, and almost always. Responses to each question were coded on a scale from 0 to 3 ; the higher the score, the smaller the perceived hearing difficulties. The total score per subject was obtained by adding the scores for 28 questions. Maximum total score of the questionnaire was 84. Additionally, the answers for each subscale were summed up (maximum score for subscale I was 24, while for the other subscales the total was 15) (MEIJER et al., 2003).

\subsection{Hearing examination}

Standard pure-tone audiometry (PTA) and transient-evoked otoacoustic emission (TEOAE) determinations were made in subjects under study. Before the hearing examinations, otoscopy was performed. Hearing examinations were carried out in a sound-proof room where the A-weighted equivalent-continuous sound pressure level of background noise did not exceed $30 \mathrm{~dB}$.

PTA was performed using an Audio Traveller Audiometer type 222 (Interacoustics) with TDH 39 headphones. Hearing threshold levels (HTLs) for air conduction were determined using an ascendingdescending technique in 5 -dB steps at the frequencies from 0.25 to $8 \mathrm{kHz}$. The mean hearing threshold levels in subgroups of subjects were analyzed. The percentage of ears with hearing threshold level exceeding $20 \mathrm{~dB}$ at any of high frequencies $(>3 \mathrm{kHz})$ and with mean hearing threshold level exceeding $20 \mathrm{~dB}$ HL at speech frequencies $(0.5,1,2$ and $4 \mathrm{kHz})$ were also calculated in the study subgroups. In order to identify early signs of NIHL the prevalence of high-frequency notches in audiograms was analyzed in the study subgroups. The notch was defined as a sharp drop in the hearing sensitivity at 4000 or $6000 \mathrm{~Hz}$ of at least $15 \mathrm{~dB}$ in relation to both best preceding threshold occurring at frequencies from 1000 to $3000(4000) \mathrm{Hz}$ and the threshold at $8000 \mathrm{~Hz}$.

A Scout Otoacoustic Emission System ver. 3.45.00 (Bio-logic System Corp.) was applied for recording and analyzing of otoacoustic emissions. TEOAE recordings of 260 averages each were collected for every subject 
at stimuli levels of about $80 \mathrm{~dB}$, using standard clicks. The artefact rejection level was set at $20 \mathrm{mPa}$. Each response was windowed from 3.5 to $16.6 \mathrm{~ms}$ post stimulus and band-pass filtered from 0 to $6000 \mathrm{~Hz}$. The total TEOAE amplitude level and the TEOAE amplitude levels for frequency bands with central frequencies $1,1.5,2,3$ and $4 \mathrm{kHz}$ were registered.

\subsection{Statistical analysis}

Answers to the questionnaire and frequency of some outcomes (e.g. prevalence of the high-frequency notched audiograms) were presented as proportions with $95 \%$ confidence intervals in the total study group and two subgroups. Differences between subgroups in proportions of answers or outcomes were assessed using chi-square test, while differences in averages of variables (e.g. age, hearing threshold levels) were analyzed using t-test for independent data or Mann-Whitney U-test, where applicable.

The STATISTICA (version 9.1. StatSoft, Inc.) software package was used for statistical analysis. All tests were conducted with assumed significance level $p<0.05$.

\section{Results}

\subsection{Study subjects characteristic and questionnaire data}

The majority $(81.0 \%)$ of participants were students who were neither occupationally exposed to noise nor to excessive sounds (music) due to frequent playing instruments. However, $25.9 \%$ of them were occasionally subjected to noise during internship or apprenticeship (Table 1).

All subjects declared usage of portable audio players. Over half of them used noisy tools (in the past or at the time of the study), about one-quarter practiced noisy motor sports and shooting. A relatively small percentages of participants declared frequent (at least a few times per month) attending music clubs and pubs $(6.9 \%)$ and loud music concerts $(1.7 \%)$. Among other risk factors for NIHL, the most frequent was smoking (50\%) (Table 1).

Regarding prevalence of other NIHL risk factors, including attending nightclubs, pubs, and music concerts, noisy hobbies, smoking, elevated blood pressure, diabetes, white-finger syndrome, light skin pigmentation, ototoxic antibiotic treatments and overweight

Table 1. Study groups characteristics. Data concern all subjects and two subgroups of subjects which were taken for further analysis.

\begin{tabular}{|l|c|c|c|}
\hline & Total & $\begin{array}{c}\text { Frequent users } \\
\text { of PAPs }\end{array}$ & $\begin{array}{c}\text { Non-frequent users } \\
\text { of PAPs }\end{array}$ \\
\hline Number of subjects & 58 & $35(60.3 \%)$ & $23(39.7 \%)$ \\
\hline Females & $29(50.0 \%)$ & $17(48.6 \%)$ & $12(52.2 \%)$ \\
\hline Males & $29(50.0 \%)$ & $17(51.4 \%)$ & $11(47.8 \%)$ \\
\hline Students & $47(81.0 \%)$ & $28(80.0 \%)$ & $19(82.6 \%)$ \\
\hline Age: mean \pm SD [years] & $22.2 \pm 2.8$ & $22.1 \pm 2.9$ & $22.5 \pm 2.8$ \\
\hline Prevalence of risk factors for NIHL & \multicolumn{2}{|c|}{ Proportion $(95 \%$ CI) [\%] } \\
\hline Occasional (occupational) exposure to noise & $25.9(16.3-38.5)$ & $22.9(11.9-39.3)$ & $30.4(15.6-51.1)$ \\
\hline Listening to PAPs & $100.0(92.6-100.0)$ & $100.0(88.2-100.0)$ & $100.0(83.1-100.0)$ \\
\hline Frequent attending to clubs, pubs, etc. & $6.9(2.3-17.0)$ & $8.6(2.3-23.3)$ & $4.3(0.0-22.7)$ \\
\hline Frequent attendance loud music concerts, etc. & $1.7(0.0-10.0)$ & $0.0 .(0.0-11.8)$ & $4.3(0.0-22.7)$ \\
\hline Practice noisy motor sports & $24.1(14.9-36.7)$ & $22.9(11.9-39.3)$ & $26.1(12.4-46.9)$ \\
\hline Shooting & $29.3(19.2-42.1)$ & $34.3(20.8-51.0)$ & $21.7(9.4-42.5)$ \\
\hline Usage of noisy tools & $56.9(44.1-68.8)$ & $57.1(40.8-72.0)$ & $56.5(36.8-74.3)$ \\
\hline Smoking & $50.0(37.6-62.4)$ & $51.4(35.6-67.0)$ & $47.8(29.3-67.0)$ \\
\hline Elevated blood pressure & $6.9(2.3-17.0)$ & $5.7(0.7-19.8)$ & $8.7(1.4-28.2)$ \\
\hline Diabetes & $0.0(0.0-7.4)$ & $0.0 .(0.0-11.8)$ & $0.0(0.0-16.9)$ \\
\hline Raynaud's phenomenon & $3.4(0.3-12.6)$ & $5.7(0.7-19.8)$ & $0.0(0.0-16.9)$ \\
\hline Light skin pigmentation & $20.7(12.2-33.0)$ & $25.7(14.1-42.3)$ & $13.0(3.9-33.2)$ \\
\hline Ototoxic antibiotic treatment & $8.6(3.4-19.2)$ & $8.6(2.3-23.3)$ & $8.7(1.4-28.2)$ \\
\hline BMI $>25$ & $29.3(19.2-42.1)$ & $31.4(18.5-48.1)$ & $26.1(12.4-46.9)$ \\
\hline $95 \%$ CI $-95 \%$ conf)
\end{tabular}

95\% CI - 95\% confidence interval; NIHL - noise induced hearing loss; PAPs - personal listening devices; BMI - body mass index. 
(BMI >25), there were no significant differences between frequent and non-frequent PAPs users.

Taking into consideration the PAP usage behaviours, $60.3 \%$ of subjects listened over $1 \mathrm{~h} /$ day and $71.4 \%$ set volume at over $50 \%$ of the maximum value (Fig. 1). Furthermore, PAPs were used $5.4 \pm 1.8$ times

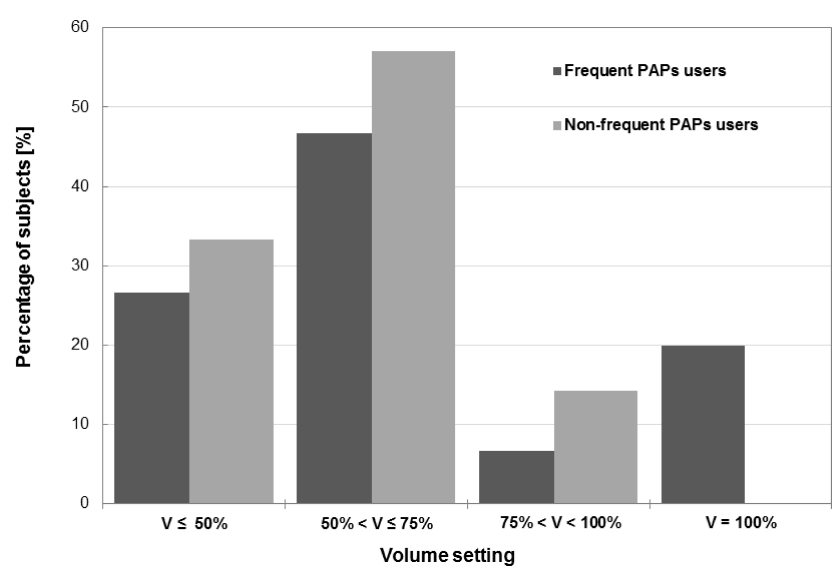

Fig. 1. Listening behaviours in frequent and non-frequent users of PAPs - volume settings.

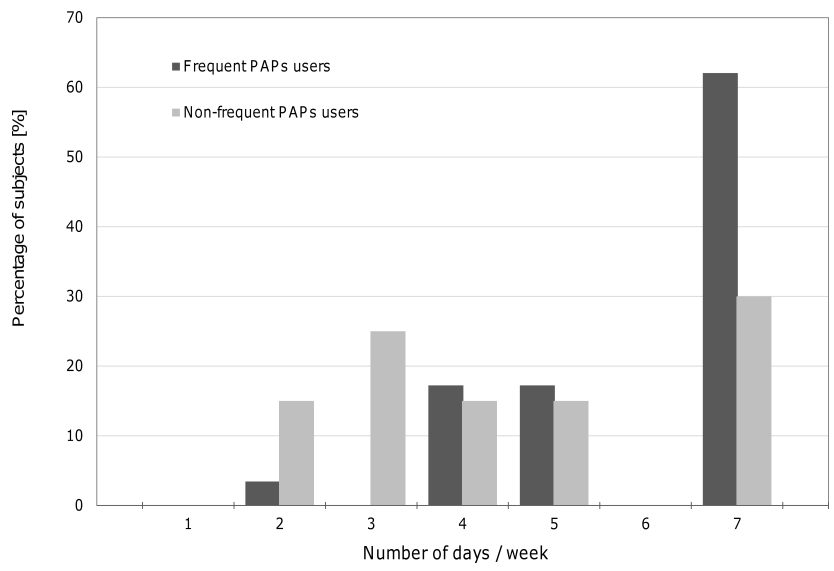

Fig. 2. Listening behaviours in frequent and non-frequent users of PAPs - number of days per week using PAPs. a week on average. The subjects' classified as frequent users listened to music through the PAPs more times a week compared to non-frequent users (6.0 \pm 1.5 vs. $4.5 \pm 1.9, p<0.05$; median values 7 and 3 , respectively) and more often listened at maximum volume setting (Figs. 1 and 2).

\subsection{Self-assessment of hearing capability}

Almost all participants (98.3\%) assessed their hearing as good. Nevertheless, some of them complained of various hearing-related symptoms (Table 2). In particular, some of them reported hearing impairment $(15.5 \%)$ and complained of difficulty in hearing whisper $(25.9 \%)$, problems with understanding speech in noisy environment $(34.5 \%)$, having hyperacusis $(6.9 \%)$ and tinnitus $(5.2 \%)$ (Table 2 ).

Frequent PAPs users more frequently complained of tinnitus and hyperacousis in comparison to nonfrequent users while the opposite relation were observed when analyzing self-reported hearing impairment as well as difficulties in hearing whisper and understanding speech in noisy environment. But these differences were not significant (Table 2).

Table 3 presents subjects' self-assessment of hearing ability in terms of the (m)AIADH. The mean total score was $87.6 \%$ of maximum value (84) which suggests no substantial hearing problems (Table 3 ). Only a few of subjects $(5.2 \%, 95 \%$ CI: $1.3-14.8 \%)$ obtained the total score under $70 \%$ of the maximum value. Relatively low scores were more frequent in subscales evaluating auditory localization (subscales II) and intelligibility in noise (subscale III), since $15.5 \%$ (95\% CI: $8.2-27.3 \%$ ) and $10.3 \%$ (95\%CI: $4.6-21.2 \%)$ of subjects scored below $70 \%$ of maximum value. However, neither significant differences in the total score nor in the scores in various subscales were noted between the frequent and non-frequent users of PAPs (Table 3).

Table 2. Incidence of self-reported hearing-related symptoms in study subjects.

\begin{tabular}{|l|c|c|c|}
\hline \multirow{2}{*}{} & Total & Frequent users of PAPs & Non-frequent users of PAPs \\
\cline { 2 - 4 } & \multicolumn{3}{|c|}{ Proportion (95\%CI) [\%] } \\
\hline Good hearing & $98.3(90.0-100.0)$ & $100.0(88.2-100.0)$ & $95.7(77.3-100)$ \\
\hline Hearing impairment & $15.5(8.2-27.3)$ & $11.4(4.1-26.7)$ & $21.7(9.4-42.5)$ \\
\hline self-reported & $10.3(4.6-21.2)$ & $8.6(2.3-23.3)$ & $13.0(3.9-33.2)$ \\
\hline noticed by family & $25.9(16.3-38.5)$ & $17.1(7.8-33.2)$ & $39.1(22.2-59.3)$ \\
\hline Difficulties with hearing/understanding & $2.9(0.0-15.8)$ & $0.0(0-16.9)$ \\
\hline whisper & $1,7(0.0-10.0)$ & $25.7(14.1-42.3)$ & $47.8(29.3-67.0)$ \\
\hline normal speech & $34.5(23.6-47.4)$ & $8.6(2.3-23.3)$ & $0.0(0.0-16.9)$ \\
\hline speech in noisy environment & $5.2(1.3-14.8)$ & $11.4(4.1-26.7)$ & $0.0(0.0-16.9)$ \\
\hline Tinnitus & $6.9(2.3-17.0)$ &
\end{tabular}

95\% CI - 95\% confidence interval; PAPs - personal listening devices. 
Table 3. Hearing ability in terms of score in the (modified) Amsterdam Inventory for Auditory Disability and Handicap in study subjects.

\begin{tabular}{|l|c|c|c|}
\hline \multirow{2}{*}{ Score in the (m)AIADH } & Total & Frequent users of PAPs & Non-frequent users of PAPs \\
\cline { 2 - 4 } & \multicolumn{3}{|c|}{ Mean \pm SD } \\
\hline Total & $73.6 \pm 7.7$ & $73.8 \pm 7.9$ & $73.3 \pm 7.5$ \\
\hline Subscale I (distinction of sounds) & $21.9 \pm 2.5$ & $21.9 \pm 2.8$ & $21.9 \pm 2.0$ \\
\hline Subscale II (auditory localization) & $12.8 \pm 2.2$ & $12.8 \pm 2.1$ & $12.7 \pm 2.3$ \\
\hline Subscale III (intelligibility in noise) & $12.2 \pm 1.3$ & $12.2 \pm 1.4$ & $12.2 \pm 1.1$ \\
\hline Subscale IV (intelligibility in quiet) & $13.4 \pm 1.3$ & $13.5 \pm 1.3$ & $13.2 \pm 1.3$ \\
\hline Subscale V (detection of sounds) & $13.3 \pm 2.0$ & $13.4 \pm 2.0$ & $13.3 \pm 2.1$ \\
\hline
\end{tabular}

(m)AIAHD - (modified) Amsterdam Inventory for Auditory Disability and Handicap; SD - standard deviation.

\subsection{Results of hearing tests}

Audiometric hearing threshold levels (HTLs) determined in study subjects are shown in Fig. 3. Generally, the majority $(81.9 \%)$ of them had HTLs (in the frequency range $1-8 \mathrm{kHz}$ ) within normal limits $(\leq 20 \mathrm{~dB} H L)$. The percent of subjects with mean HTL at speech frequencies $(0.5,1,2$ and $4 \mathrm{kHz})$ exceeding $20 \mathrm{~dB}$ HL was higher in non-frequent users than frequent users $(6.5$ vs. $0.0 \%, p<0.05)$. The percent of ears with HTL exceeding $20 \mathrm{~dB}$ HL in any of high frequencies $(3-8 \mathrm{kHz})$ was also higher in the subgroup of non-frequent PAPs users $(21.7 \%)$ compared to frequent users $(10.0 \%$ ) (Table 4 ). However, the difference was not statistically significant.

Typical NIHL notches at 4000 or $6000 \mathrm{~Hz}$ of at least $15 \mathrm{~dB}$ depth were observed in $6.9 \%$ (Table 4 ). Majority of them (87.5\%) occurred at frequency of $6000 \mathrm{~Hz}$. No bilateral notching at any frequency was noted. There were no statistically significant differences in prevalence of notches between subgroups of subjects, although they appear to be more frequent

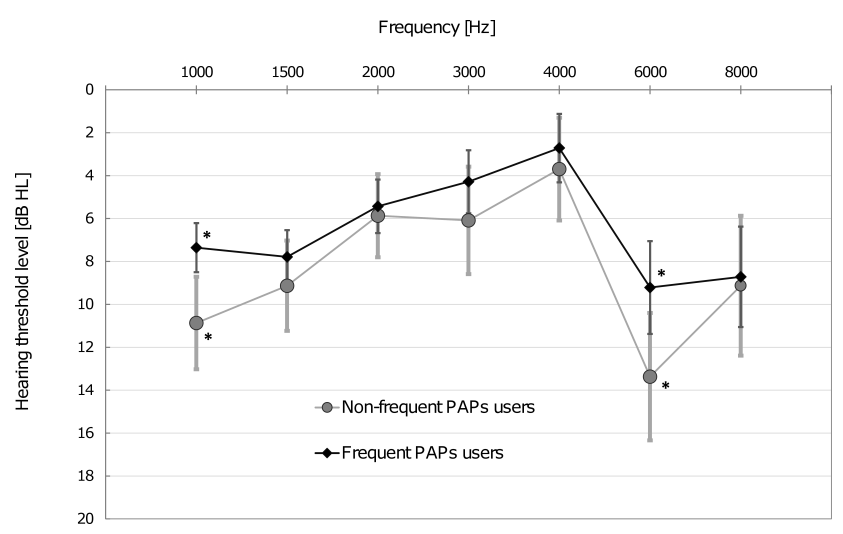

Fig. 3. Audiometric hearing threshold levels (mean $\pm 95 \%$ confidence interval) in frequent and no-frequent PAPs. Significant differences between subgroups were marked by $\left(^{*}\right)$.

in non-frequent users of PAPs. Furthermore, the latter subjects had significantly higher (worse) HTLs (at 1000 and $6000 \mathrm{~Hz}$ ) as compared to frequent PAPs users (Fig. 3).

Table 4. Summary results of pure-tone audiometry in study subjects.

\begin{tabular}{|c|c|c|c|}
\hline \multirow{2}{*}{ Pure tone audiometry results } & Total & Frequent users of PAPs & Non-frequent users of PAPs \\
\hline & \multicolumn{3}{|c|}{ Proportion of audiograms (95\% CI) [\%] } \\
\hline \multicolumn{4}{|l|}{ Mean hearing threshold level } \\
\hline at frequencies of $0.5,1,2$ and $4 \mathrm{kHz}>20 \mathrm{~dB} \mathrm{HL}$ & $2.6(0.6-7.7)$ & $0.0(0.0-6.2)^{*}$ & $6.5(1.7-18.3)^{*}$ \\
\hline in frequency range $3-8 \mathrm{kHz}>20 \mathrm{~dB} \mathrm{HL}$ & $3.4(1.1-8.9)$ & $2.9(0.3-10.6)$ & $4.3(0.5-15.5)$ \\
\hline \multicolumn{4}{|l|}{ Any hearing threshold level } \\
\hline at frequencies of $0.5,1,2$ and $4 \mathrm{kHz}>20 \mathrm{~dB} \mathrm{HL}$ & $6.9(3.4-13.3)$ & $2.9(0.3-10.6)^{*}$ & $13.0(5.8-26.2)^{*}$ \\
\hline in frequency range $3-8 \mathrm{kHz}>20 \mathrm{~dB} \mathrm{HL}$ & $14.7(9.3-22.4)$ & $10.0(4.7-19.6)$ & $21.7(12.2-35.8)$ \\
\hline \multicolumn{4}{|l|}{ High-frequency notch } \\
\hline total & $6.9(3.4-13.3)$ & $5.7(1.9-14.3)$ & $8.7(3.0-21.0)$ \\
\hline right ear & $3.4(0.3-12.6)$ & $2.9(0.0-15.8)$ & $4.3(0.0-22.7)$ \\
\hline left ear & $10.3(4.6-21.2)$ & $8.6(2.3-23.3)$ & $13.0(3.9-33.2)$ \\
\hline bilateral notch & $0.0(0.0-7.4)$ & $0.0(0.0-11.8)$ & $0.0(0.0-16.9)$ \\
\hline
\end{tabular}

95\% CI - 95\% confidence interval; * Significant differences between subgroups $(p<0.05)$. 
Results of TEOAE testing are summarized in Fig. 4 and 5. Generally, in all analyzed ears the reproducibility of total response was greater than $60 \%$ and signal to noise ratio (SNR) exceeded 6 dB. Furthermore, similarly to audiometry, TEOAE indicated worse hearing in non-frequent compared to frequent users of PAPs. The non-frequent users had lower SNR (both for the whole response and for frequency bands of $1.5-4 \mathrm{kHz}$ ) and smaller reproducibility (both for the whole response and for all frequency bands of $1.0-4 \mathrm{kHz}$, excluding $3 \mathrm{kHz}$ ) (Fig. 4). However, these differences were not significant.

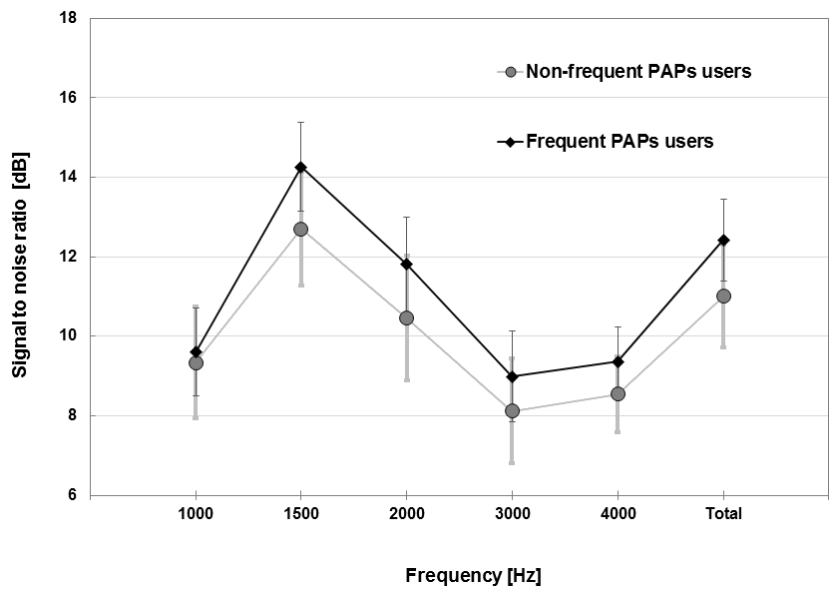

Fig. 4. TEOAEs (mean $\pm 95 \%$ confidence interval) in frequent and non-frequent PAPs users - signal to noise ratio. No significant differences were observed between subgroups of subjects.

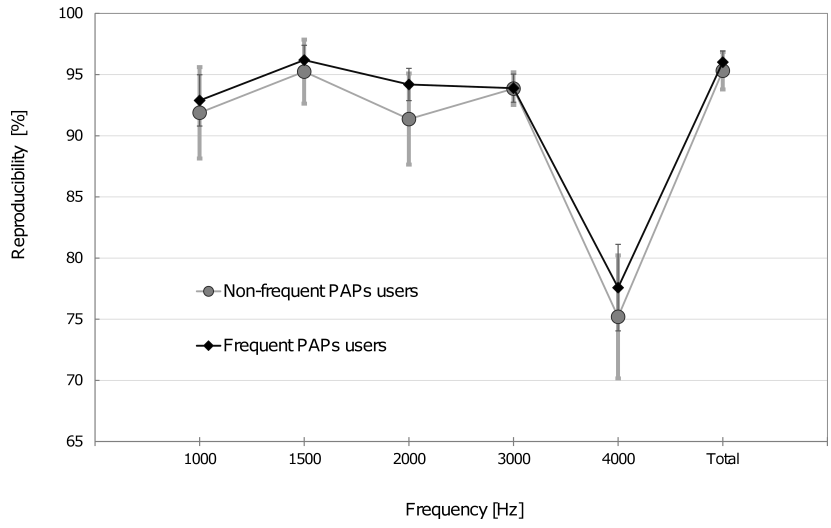

Fig. 5. TEOAEs (mean $\pm 95 \%$ confidence interval) in frequent and non-frequent PAPs users - reproducibility of response. No significant differences were observed between subgroups of subjects.

\section{Disscusion}

The overall objective of this study was to analyze the possible impact of frequent usage of portable audio players on hearing ability in young adults. It was designed as the initial preparatory stage to the relevant cross-sectional study aimed at evaluation of the prevalence and risk of noise-induced hearing loss due to frequent listening to PAPs in young Polish population. Therefore, this study was limited to hearing tests and questionnaire surveys in young volunteers. Neither portable audio players' output capabilities nor volunteers' preferred output levels were evaluated based on sound pressure level measurements.

However, earlier Rogowski et al. (2001) investigated the preferred levels of music reproduction from the portable audio players in 284 pupils of Warsaw secondary schools. They measured sound pressure level (SPL) under headphones attached to the IEC 711 standard acoustic coupler (connected to sound level meter) and found that the average user of a portable player was exposed to the A-weighted equivalent-continuous sound pressure level of $103 \mathrm{~dB}$, while instantaneous SPL reached $117 \mathrm{~dB}$ for $1 \%$ of the duration of exposure.

It is worth underlining that in order to compensate for the acoustical effects of the head and pinna and to allow comparisons to the applicable regulatory limits, measured levels should be either corrected using a single number of 8 to $10 \mathrm{~dB}$ or through a frequencydependent equalization network (NASSRALlaH et al., 2013). Such corrections were not applied in the aforesaid study. However, even when subtracting a $10 \mathrm{~dB}$ correction factor, the resultant sound pressure level exceeded $90 \mathrm{dBA}$, indicating that young users of portable audio players were exposed to sounds at levels that might cause hearing loss.

In this study, all participants declared usage of PAPs. However, only $60.3 \%$ of them listened over 1 hour per day. Furthermore, those subjects more often used PAPs and set volume at maximum value. Thus, those subjects who declared using over $1 \mathrm{~h} /$ day were classified as frequent PAPs users, while the others were classified as non-frequent users.

It is known that individual susceptibility (or vulnerability) to noise, along with the degree of hearing loss, varies greatly among people. It is believed that NIHL is a complex disease resulting from the interaction between intrinsic and environmental factors. Besides well-known environmental factors contributing to NIHL, such as exposure to occupational and non-occupational noise, some others may also play a role, including smoking, elevated blood pressure, diabetes, cholesterol levels, skin pigmentation (SLiWinska-KowalsKa et al., 2006).

Regarding other noisy or loud activities, a relatively small percentage of participants declared frequent (at least a few times per month) attending music clubs and pubs (6.9\%) and loud music concerts (1.7\%). On the other hand, over half of them used (at the time of the study or in the past) noisy tools, while over onequarter practiced noisy motor sports or shooting and were occasionally exposed to occupational noise.

Additional NHIL risk factors, excluding smoking, were rather rare in the study. It is worth underlining 
that a half of subjects reported smoking at the time of the study or in the past. Furthermore, they were (or have been) smokers up to 10 years (about 2 years on average). But besides PAP-listening habits, there were no significant differences in the aforesaid NIHL risk factors between frequent and non-frequent PAPs users.

Generally, the majority of study subjects had audiometric hearing levels within normal limits $(\leq 20 \mathrm{~dB} H \mathrm{HL})$. Thus, to identify early signs of NIHL the prevalence of high-frequency notches (i.e. a sharp drop in the hearing sensitivity at 4000 or $6000 \mathrm{~Hz}$ ) in audiograms were analyzed. It was found that typical high-frequency notches (mainly at $6000 \mathrm{~Hz}$ ) were observed in $6.9 \%$ of analyzed audiograms.

NIHL develops very slowly over the years of exposure. Thus, the effects of overexposure to loud music could be difficult to single out in teenagers with relatively short duration of PAPs usage. For example, according to the ISO 1999 (2013) model, a shift of hearing threshold greater or equal to $25 \mathrm{~dB}$ in speech frequencies should not take place in males with healthy ears, provided the exposure to noise does not exceed 15 years for $85 \mathrm{dBA}$ level and 6 years for $90 \mathrm{dBA}$ level (ISO 1999, 2013). Thus, it is not surprising that in this study the proportion of NIHL notches in audiograms did not differ significantly between frequent and non-frequent PAPs users. However, significant differences in the prevalence of hearing impairment in speech and high frequency ranges between these subgroups were observed. But contrary to our expectations nonfrequent users had worse HTLs than frequent users of PAPs. The explanation for this finding could be that non-frequent users attended more frequently loud music concerts.

The literature concerning recreational exposures to loud sounds, including listening to music through PAPs, is quite extensive. However, the data on exposure-response relationship between the exposure to music listened to through PAPs and permanent hearing loss measured by quantifiable hearing test are very scarce.

According to the Malaysian and Canadian studies exposures to loud music listened to through PAPs may result in hearing threshold shifts, provided the level of music is high and the duration of exposure is long (more than 5 years). The results of these studies show that if the exposure to music is relatively short (mean 3.2 years), typical signs of NIHL are not detected in the standard audiometric frequencies $(0.25$ $8 \mathrm{kHz}$ ) but can be visible at extended high frequencies (Sulaiman et al., 2013). As anticipated, the early stages of NIHL can also be recognized by decreasing the signals of otoacoustic emissions (SUlAiman et al., 2014). Similar decrease in TEOAE was found in our study. Furthermore, using PAPs for a longer time was shown to be associated with increased incidence of permanent hearing loss and worsening of hearing thresh- olds at standard test frequencies related to the exposure level (FEDER et al., 2013; SUlAIMAN et al., 2014).

Unfortunately, in our study the duration (in years) of the PAPs usage was not analyzed. However, besides pure tone audiometry, the TEOAEs determinations were conducted in participants. In all analysed ears the reproducibility of total response was greater than $60 \%$ and signal to noise ratio (SNR) exceeded $6 \mathrm{~dB}$. TEOAE indicated better hearing in frequent compared to non-frequent users of PAPs which was in accordance with the results of pure-tone audiometry.

\section{Conclusion}

Although data presented here did not support the thesis that frequent usage of PAPs was associated with higher risk of worsening hearing ability in young adults, further studies are needed.

\section{Acknowledgments}

This study was supported by the Ministry of Science and Higher Education of Poland (Grant IMP 18.2/2012-2013).

\section{References}

1. Breinbauer H.A., Anabalón B., Gutierrez D., Cárcamo R., Olivares C., Caro J. (2012), Output capabilities of personal music players and assessment of preferred listening levels of test subjects: outlining recommendations for preventing music-induced hearing loss, Laryngoscope, 122, 11, 2549-2556.

2. Feder K., Marro L., Keith S.E., Michaud D.S. (2013), Audiometric thresholds and portable digital audio player user listening habits, International Journal of Audiology, 52, 9, 606-616.

3. Figueiredo R.R., Azevedo A.A., Oliveira P.M., Amorim S.P., Rios A.G., BAptista V. (2011), Incidence of tinnitus in mp3 player users, Brazilian Journal of Otorhinolaryngology, 77, 3, 293-298.

4. ISO 1999:2013, Acoustics - Estimation of noiseinduced hearing loss. International Organization for Standardization.

5. Keith S.E., Michaud D.S., Feder K., Haider I., Marro L., Thompson E., Marcoux A.M. (2011), MP3 player listening sound pressure levels among 10 to 17 year old students, Journal of the Acoustical Society of America, 130, 5, 2756-2764.

6. Meijer A.G.W., Wit H.P., TenVergert E.M. (2003), Reliability and validity of the modified Amsterdam Inventory for Auditory Disability and Handicap, International Journal of Audiology, 42, 220-226.

7. Muchnik C., Amir N., Shabtai E., KaplanNeEman R. (2012), Preferred listening levels of personal listening devices in young teenagers: self-reports and physical measurements, International Journal of Audiology, 51, 4, 287-293. 
8. Nassrallah F., Giguere Ch., Dajani H.R. (2014), Measurement methods of noise exposure communication headset used in various occupational settings, Proceedings of 11th International Congress on Noise as a Public Health Problem (ICBEN) 2014, Nara, Japan [CD-ROM]

9. Pellegrino E., Lorini C., Allodi G., BuonamiCi C., Garofalo G., Bonaccorsi G. (2013), Musiclistening habits with MP3 player in a group of adolescents: a descriptive survey, Annali Di Igiene, 25, 5, 367-376.

10. Portnuff C.D., Fligor B.J., Arehart K.H. (2011), Teenage use of portable listening devices: a hazard to hearing?, Journal of the American Academy of Audiology, 22, 10, 663-677.

11. Portnuff C.D., Fligor B.J., Arehart K.H. (2013), Self-report and long-term field measures of MP3 player use: how accurate is self-report?, International Journal of Audiology, 52, 1, 33-40.

12. Rogowski P., Rościszewska T., Jaroszewski A. (2001), Sound reproduction levels in portable players used by pupils in Warsaw secondary schools, Archives of Acoustics, 26, 1, 3-10.
13. Sliwinska-Kowalska M., Dudarewicz A., KotyLO P., Zamyslowska-SzmytKe E., PAWlacZYKLuszczynska M., Gajda-Szadkowska A. (2006), Individual susceptibility to noise-induced hearing loss: choosing an optimal method of retrospective classification of workers into noise-susceptible and noiseresistant groups, International Journal of Occupational Medicine and Environmental Health, 19, 4, 235-245.

14. Sulaiman A.H., Husain R., Seluakumaran K. (2014), Evaluation of early hearing damage in personal listening device users using extended highfrequency audiometry and otoacoustic emissions, European Archives of Oto-Rhino-Laryngology, 271, 6, 1463-1470.

15. Sulaiman A.H., Seluakumaran K., Husain R. (2013), Hearing risk associated with the usage of personal listening devices among urban high school students in Malaysia, Public Health, 127, 8, 710-715.

16. Vogel I., Brug J., Van der Ploeg C.P., RaAt H. (2011), Adolescents risky MP3-player listening and its psychosocial correlates, Health Education Research, 26, 2, 254-264. 